\title{
Fenofibrate decreased microalbuminuria in the type 2 diabetes patients with hypertriglyceridemia
}

\author{
Xiaomeng Sun, Jia Liu and Guang Wang*
}

\begin{abstract}
Background: This study was to research the efficacy of fenofibrate in the treatment of microalbuminuria in the patients with type 2 diabetes mellitus (T2DM) and hypertriglyceridemia.

Methods: Type 2 diabetic patients (56) with microalbuminuria and hypertriglyceridemia aged 30 to 75 were randomly divided into the fenofibrate treatment $\operatorname{group}(n=28)$ and the control group $(n=28)$ for 180 days. Urinary microalbumin /creatinine ratio (UACR) and other metabolic parameters were compared at baseline, during treatment and after treatment.

Results: After 180 days, the reduction of level of fasting blood glucose (FBG) and glycosylated hemoglobin (HbA1c) between two groups showed no difference. In the treatment group, uric acid (UA) (296.42 \pm 56.41 vs $372.46 \pm$ 72.78), triglyceride (TG) $[1.51(1.17,2.06)$ vs $3.04(2.21,3.29)]$, and UACR $[36.45(15.78,102.41)$ vs $129.00(53.00,226.25)]$ were significantly decreased compared with the baseline. The high-density lipoprotein cholesterol (HDL-C) levels were significantly increased (1.22 \pm 0.26 vs $1.09 \pm 0.24)$ compared with the baseline. The decrease in UACR [44.05(-179.47, -12.16$)$ vs $-8.15(-59.69,41.94)]$ in treatment group was significantly higher compared with the control group. The decrease in UACR was positively associated with the decreases in TG $(r=0.447, P=0.042)$ and UA $(r=0.478, P=0.024)$ after fenofibrate treatment.
\end{abstract}

Conclusion: In the patients with hypertriglyceridemia and type 2 diabetes mellitus, fenofibrate can improve microalbuminuria and do not increase the deterioration of glomerular filtration rate.

Trial registration: ClinicalTrials.gov identifier: NCT02314533, 2014.12.9

Keywords: Type 2 diabetes mellitus, Hypertriglyceridemia, Fenofibrate, Urinary albumin/creatinine ratio

\section{Background}

Diabetic nephropathy (DN) has been considered as one of the important microvascular complication of diabetes mellitus, if left untreated, it can lead to kidney failure and renal dialysis or kidney transplantation [1]. Hypoglycemic, hypotensive, and lipid lowering drugs are the main treatment options for DN at present. However,

\footnotetext{
*Correspondence: drwg6688@126.com

Department of Endocrinology, Beijing Chao-Yang Hospital, Capital Medical University, 8 Gongren Tiyuchang Nanlu, Chaoyang District, Beijing 100020, P. R. China
}

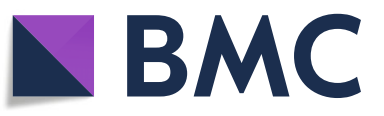

there are still some patients who continue to experience DN progression even after intensive hypoglycemic therapy, statin treatment, and blood pressure reaching the standard levels. Our previous studies have shown that fenofibrate therapy can significantly reduce insulin resistance and the secretory load of $\beta$ cells [2]. Fenofibrate could improve plasma level of tetrahydrobiopterin (BH4) and protect endothelial function [3, 4]. The Fenofibrate Intervention and Event Lowering in Diabetes (FIELD) study suggested that treatment of fenofibrate can reduce albuminuria and prevent the progression of diabetic

(c) The Author(s). 2020 Open Access This article is licensed under a Creative Commons Attribution 4.0 International License, which permits use, sharing, adaptation, distribution and reproduction in any medium or format, as long as you give appropriate credit to the original author(s) and the source, provide a link to the Creative Commons licence, and indicate if changes were made. The images or other third party material in this article are included in the article's Creative Commons licence, unless indicated otherwise in a credit line to the material. If material is not included in the article's Creative Commons licence and your intended use is not permitted by statutory regulation or exceeds the permitted use, you will need to obtain permission directly from the copyright holder. To view a copy of this licence, visit http://creativecommons.org/licenses/by/4.0/. The Creative Commons Public Domain Dedication waiver (http://creativecommons.org/publicdomain/zero/1.0/) applies to the data made available in this article, unless otherwise stated in a credit line to the data. 
nephropathy $[5,6]$. The Action to Control Cardiovascular Risk in Diabetes (ACCORD) study suggested that a lower incidence of both microalbuminuria and macroalbuminuria was noted in the fenofibrate group [7]. However, all these studies are long-term studies with observation periods of 3-5 years. It is unclear whether fenofibrate could impact microalbuminuria on the early stage of the treatment. Moreover, urinary microalbumin/ creatinine ratio (UACR) is less affected by diet and urine concentration. We designed this study to evaluate fenofibrate's effect on microalbuminuria change and estimated glomerular filtration rate (eGFR) in Chinese type 2 diabetes patients with hypertriglyceridemia.

\section{Methods}

\section{Study design and participants}

This is a randomized (no placebo) controlled study to evaluate the efficacy of fenofibrate on microalbuminuria in type 2 diabetes mellitus (T2DM) patients with hypertriglyceridemia. The study enrolled 56 subjects to meet scientific and regulatory objectives without enrolling an undue number of subjects in alignment with ethical considerations. A total of 56 T2DM patients were enrolled by the endocrinology department at Beijing Chao-Yang Hospital during February 2015 and July 2018. The diagnosis of T2DM was in accordance with the World Health Organization (WHO) criteria of 2013 [8]. All the patients with HbAlc levels $<8 \%$ and with microalbuminuria were eligible for the study. Diagnosis of microalbuminuria was determined by two morning spot urine samples on different days, defined as UACR between 30 and $300 \mathrm{mg} / \mathrm{g}$. All patients had been treated with statin monotherapy at low to moderate doses at least 2 months prior to enrollment and planned to continue the same type and dose of statin, but their triglyceride (TG) levels were still greater than $1.7 \mathrm{mmol} / \mathrm{L}$ and lower than $5.6 \mathrm{mmol} / \mathrm{L}$. Additionally, the blood pressure levels of all the patients should lower than 140/90 $\mathrm{mmHg}$. The 56 patients were randomly divided to the fenofibrate treatment group (group A) or control group (group B) according to the random number table after subject enrollment condition was confirmed. Fenofibrate (Lipanthy $\mathrm{l}^{\circ}$ ) $200 \mathrm{mg}$ capsule was administered orally with breakfast once daily according to the Chinese prescription information of Lipanthyl ${ }^{\circ}$. During treatment, the hypoglycemic and hypotensive drugs were no longer adjusted. Hypoglycemic drugs included metformin, $\alpha-$ glucosidase inhibitors, sulfonylureas, glinides, and insulin. The main lipid-lowering drugs were atorvastatin, rosuvastatin, simvastatin, and pravastatin. The exclusion criteria were pregnancy or possible pregnancy, cardiovascular disease (CVD), hepatic insufficiency (ALT or AST $>2 * \mathrm{ULN}$ ), renal insufficiency [estimate glomerular filtration rate (eGFR) $<60 \mathrm{ml} / \mathrm{min}$ estimated from
Modification of Diet in Renal Disease (MDRD) equation], thyroid disease, infectious disease, cancer, and/or systemic inflammatory diseases. The study received approval from the Ethics Committee of Beijing Chao-yang Hospital. All participants gave their written, informed consent to participate. This study was registered with ClinicalTrials.gov. (ClinicalTrials.gov identifier: NCT02314533). The study was in compliance with the content of the Declaration of Helsinki. All participants were required to attend 3 study visits: visit 1 , the screening visit; visit 2 , fenofibrate treatment for 90 days; visit 3 , fenofibrate treatment for 180 days. Fasting blood samples and urine sample were collected at every visit. All subjects underwent clinical assessments of age, sex, height, and weight at the first visit. Age, and weight were assessed at every visit. The total cholesterol (TC), highdensity lipoprotein cholesterol (HDL-C), TG, lowdensity lipoprotein cholesterol (LDL-C), serum creatinine (Scr), urinary creatinine, and uric acid (UA) were enzymatically determined (Siemens Advia 2400, Siemens Healthcare Diagnostics Inc., Tarrytown, New York, USA). Urinary albumin was measured using immunoturbidimetric assay (Siemens Advia 2400, Siemens Healthcare Diagnostics Inc., Tarrytown, New York, USA). Fasting serum insulin (FINS) was measured using the chemiluminescence immunoassay (System Centaur XP, reference interval:1.9-23 mIU/mL; Siemens Healthcare Diagnostics, Inc., Tarrytown, New York, USA). HbA1c was determined by high-performance liquid chromatography (HLC-723G7 analyzer, reference interval: 4-6\%; Tosoh Corporation, Tokyo, Japan). Body mass index (BMI) was calculated as weight $(\mathrm{kg}) /$ height $^{2}\left(\mathrm{~m}^{2}\right)$. The homeostasis model assessment index of insulin resistance (HOMA-IR) was calculated as follows: HOMA$\mathrm{IR}=$ fasting insulin $(\mathrm{uU} / \mathrm{mL}) \times$ fasting plasma glucose $(\mathrm{mmol} / \mathrm{L}) / 22.5$; The homeostasis model assessment for $\beta$-cell function(HOMA- $\beta$ ) was calculated as follows: HOMA $-\beta=20 \times$ fasting insulin $(\mathrm{uU} / \mathrm{mL}) /($ fasting plasma glucose $(\mathrm{mmol} / \mathrm{L})-3.5) \times 100 \%$; UACR $=$ urinary microalbumin $(\mathrm{mg} / \mathrm{dL}) \times 1000 /$ urinary creatinine $(\mathrm{umol} / \mathrm{L}) \times$ $1000 / 113.1 \times 1000 / 100(\mathrm{mg} / \mathrm{g})$; eGFR estimated using the MDRD equation: male: eGFR $=186 \times \mathrm{Cr}(\mathrm{mg} / \mathrm{dl})$ $1.154 \times($ age $)-0.203\left(\mathrm{ml} / \mathrm{min} / 1.73 \mathrm{~m}^{2}\right)$; female: eGFR = $186 \times \mathrm{Cr}(\mathrm{mg} / \mathrm{dl})-1.154 \times($ age $)-0.203 \times 0.742 \quad(\mathrm{ml} / \mathrm{min} /$ $\left.1.73 \mathrm{~m}^{2}\right)$.

\section{Statistical analyses}

Data were analyzed with SPSS version 19.0 (IBM Corp., Armonk, NY, USA). Continuous data, such as, BMI, age, systolic blood pressure (SBP), diastolic blood pressure (DBP), fasting blood glucose (FBG), HbA1C, TC, HDLC, LDL-C, UA, and Scr were expressed as mean \pm standard deviation. Because some data, such as TG, FINS, HOMA-IR, HOMA- $\beta$, eGFR, and UACR were not 
normally distributed, the values are provided as medians (interquartile range, IQR). Normally distributed data were analyzed by t-test. Logarithmically transformed values were used in the statistical analyses. Two-tails paired t-test was used in parameters from the baseline values within group. Independent sample t-test was used to compare differences between groups at baseline and after treatment. The correlation of the changes in UACR and other parameters were analyzed using the Spearman correlation. The differences of proportions were analyzed by chi-square test. All statistical tests are twotailed, with $P$-value $<0.05$ considered to be statistically significant.

\section{Results}

Patients' baseline characteristics

The baseline clinical characteristics are summarized in Table 1. No differences were found in age, sex, BMI, SBP, DBP, FBG, HbA1c, TC, TG, HDL-C, LDL-C, UA, Scr, FINS, HOMA-IR, HOMA- $\beta$, eGFR, UACR, or the use of antihypertensive drugs, cholesterol-lowering drugs, and hypoglycemic drugs in two groups (Table 1).

\section{Changes in metabolic parameters after fenofibrate treatment}

Compared with the baseline, FBG and HbA1c all significantly decreased in the treatment group and the control group at 90 days and 180 days. There was no difference between the two groups in FBG and HbA1c at 90 days and 180 days.

In the treatment group, after 90 days of fenofibrate treatment, we found that the levels of UA $(290.42 \pm$ 76.76 vs $372.46 \pm 72.78)$, and TG $[1.71(1.27,2.31)$ vs $3.04(2.21,3.29)]$ were significantly lower than the baseline. After 180 days of fenofibrate treatment, the levels of UA $(296.42 \pm 56.41$ vs $372.46 \pm 72.78)$, TG [1.51 (1.17, $2.06)$ vs $3.04(2.21,3.29)]$, UACR $[36.45(15.78,102.41)$ vs $129.00(53.00,226.25)]$, and HOMA-IR [2.77(1.98, 3.44) vs $4.27(3.05,5.35)]$ were significantly lower at 180 days than at baseline, while HDL-C $(1.22 \pm 0.26$ vs $1.09 \pm$ 0.24 ) was significantly higher at 180 days than at baseline(all $P<0.05)$. No differences were found in BMI, TC, LDL-C, Scr, HOMA- $\beta$, and eGFR among the three visits.

In the control group, HOMA-IR $[3.12(2.01,3.87)$ vs $4.50(3.13,5.95)]$ were significantly lower at 180 days than at baseline. There were no differences in BMI, TC, TG, HDL-C, LDL-C, UA, Scr, FINS, HOMA- $\beta$, eGFR, and UACR among the three visits.

The decreases in UA $[-92.5(-145,-21)$ vs $0.00(-$ $60.00,45.00)]$, TG $[-1.27(-1.77,-0.24)$ vs-0.64(-0.96, $0.42)]$ and eGFR $[-10.70(-22.78,-8.31)$ vs $-2.27(-$ $7.33,4.63)$ ]in the treatment group showed greater decline compared the control group at 90 days. The decreases in UACR $[-44.05(-179.47,-12.16)$ vs $-8.15(-59.69$,
41.94)], UA [-66(-111.00, -34.00$)$ vs $-16.00(-43.75$, $-16.00)]$ and TG $[-1.91(-1.12,-0.53)$ vs- $0.22(-1.21$, 0.19)] showed greater decline compared the control group at 180 days. The increase in Scr was significantly higher at 90 days in the treatment group than the control group. The increase in HDL-C was significantly higher at 180 days in treatment group than the control group. There was no difference between the two groups in the increase of Scr and the decrease of eGFR at 180 days. (Table 2).

\section{Correlations between the decrease in UACR and changes in other variables after 180 days fenofibrate treatment}

In the fenofibrate group, the decrease in UACR ( $\triangle \mathrm{UACR})$ was positively associated with the decreases in $\mathrm{TG}(\Delta \mathrm{TG})(r=0.447, P=0.042)$ and $\mathrm{UA}(\Delta \mathrm{UA})(r=0.478$, $P=0.024)$ after fenofibrate treatment (Fig. 1). In our study, we found no significant relationship between the decrease in UACR and the change of age, BMI, TC, HDL-C, LDL-C, Scr, FINS, HOMA-IR, or eGFR.

\section{Discussion}

In this study, at 180 days, compared with the control group, the levels of UACR, UA, and TG were significantly decreased while the levels of HDL-C were significantly increased. The decreases in UACR, UA and TG showed greater decline compared the control group at 180 days. Correlation analysis suggested that the decrease in UACR was positively associated with the decrease in TG and UA after fenofibrate treatment. We found that on the basis of the treatment of blood glucose, blood pressure, and lipids, the treatment of controlling TG could still further reduce UACR.

$\mathrm{DN}$ is a very important diabetic microvascular complication. If left untreated, it can lead to hemodialysis and renal transplantation [1]. However, DN can be reversed if diagnosed and treated it on the early stage. Glomerulosclerosis and tubular necrosis, thickening of the basement membranes of the glomeruli and tubules, and dilation of mesangial cells all contribute to the development of DN. These changes can lead to proteinuria, the level of serum creatinine increased, and eventually to decreased glomerular filtration rate [9]. Diabetes and hyperlipidemia cause renal lipid accumulation. At the same time, lipid toxicity due to accumulation of lipids in the mesangium may accelerate the progression of DN [10]. Several studies have shown that peroxisome proliferator-activated receptor $\alpha$ (PPAR $\alpha)$ agonist could inhibit renal inflammation and fibrosis and prevent renal oxidative stress $[11,12]$. Our previous studies have shown that fenofibrate therapy can significantly reduce insulin resistance and the secretory load of $\beta$ cells [2]. Fenofibrate could improve plasma levels of tetrahydrobiopterin (BH4) by increasing the guanosine 5- 
Table 1 Clinical characteristics at baseline parameters and of all subjects

\begin{tabular}{|c|c|c|c|}
\hline Group & Control group $(n=28)$ & Fenofibrate group $(n=28)$ & $P$ \\
\hline Sex (male/\%) & $17 / 60.7$ & $20 / 71.4$ & 0.604 \\
\hline Age (year) & $56.03 \pm 12.32$ & $54.64 \pm 10.09$ & 0.593 \\
\hline Duration of diabetes (years) & $5.21 \pm 2.02$ & $5.83 \pm 1.39$ & 0.716 \\
\hline Hypertension (number/\%) & $10 / 35.7$ & $11 / 39.3$ & 0.500 \\
\hline AECI/ARB (number/\%) & $7 / 25.0$ & $8 / 28.6$ & 0.768 \\
\hline CCB (number/\%) & $5 / 17.9$ & $5 / 17.9$ & 0.636 \\
\hline Metformin (number/\%) & $15,53.6$ & $13,46.4$ & 0.601 \\
\hline a-Glucosidase inhibitors (number/\%) & $20,71.42$ & $22,78.6$ & 0.546 \\
\hline Sulfonylureas (number/\%) & $12,42.9$ & $11,39.3$ & 0.791 \\
\hline Glinides (number/\%) & $10,35.7$ & $11,39.3$ & 0.787 \\
\hline Insulin (number/\%) & $6,21.4$ & $8,28.6$ & 0.786 \\
\hline Insulin/Oral medications (\%) & 22.2 & 28.6 & 0.372 \\
\hline Simvastatin (number/\%) & $12 / 42.9$ & $10 / 35.7$ & 0.392 \\
\hline Atorvastatin (number/\%) & $9 / 28.0$ & $10 / 35.7$ & 0.591 \\
\hline Rosuvastatin (number/\%) & $3 / 10.7$ & $2 / 7.1$ & 0.500 \\
\hline pravastatin(number/\%) & $4 / 14.3$ & $6 / 21.4$ & 0.364 \\
\hline $\mathrm{SBP}(\mathrm{mmHg})$ & $137.75 \pm 13.77$ & $137.71 \pm 9.59$ & 0.996 \\
\hline $\mathrm{DBP}(\mathrm{mmHg})$ & $75.00 \pm 5.60$ & $76.29 \pm 7.87$ & 0.782 \\
\hline $\mathrm{BMI}, \mathrm{kg} / \mathrm{m}^{2}$ & $27.28 \pm 3.99$ & $28.32 \pm 4.36$ & 0.429 \\
\hline $\mathrm{FPG}, \mathrm{mmol} / \mathrm{L}$ & $7.92 \pm 2.16$ & $8.27 \pm 1.31$ & 0.606 \\
\hline $\mathrm{HbA} 1 \mathrm{c}, \%$ & $7.62 \pm 0.87$ & $7.48 \pm 0.86$ & 0.480 \\
\hline $\mathrm{TG}, \mathrm{mmol} / \mathrm{L}$ & $2.97(2.13,3,31)$ & $3.04(2.21,3.29)$ & 0.606 \\
\hline $\mathrm{TC}, \mathrm{mmol} / \mathrm{L}$ & $4.59 \pm 1.14$ & $4.79 \pm 1.01$ & 0.474 \\
\hline LDL-C, mmol/L & $2.47 \pm 0.90$ & $2.55 \pm 0.94$ & 0.670 \\
\hline $\mathrm{HDL}-\mathrm{C}, \mathrm{mmol} / \mathrm{L}$ & $1.02 \pm 0.20$ & $1.09 \pm 0.24$ & 0.275 \\
\hline $\mathrm{Scr}, \mu \mathrm{mol} / \mathrm{L}$ & $69.56 \pm 15.43$ & $65.46 \pm 20.98$ & 0.349 \\
\hline $\mathrm{UA}, \mu \mathrm{mol} / \mathrm{L}$ & $388.44 \pm 126.99$ & $372.46 \pm 72.78$ & 0.803 \\
\hline UACR, mg/g & $105.00(64.00,165.00)$ & $129.00(53.00,226.25)$ & 0.095 \\
\hline $\mathrm{eGFR} \mathrm{ml} / \mathrm{min} / 1.73 \mathrm{~m}^{2}$ & $94.01(80.95,120.95)$ & $105.36(99.68,116.92)$ & 0.066 \\
\hline $\mathrm{FINS}, \mu \mathrm{IU} / \mathrm{mL}$ & $12.9(6.75,15.78)$ & $12.05(8.35,14.95)$ & 0.101 \\
\hline HOMA-IR & $4.50(3.13,5.95)$ & $4.27(3.05,5.35)$ & 0.105 \\
\hline HOMA- $\beta$ & $42.04(25.33,75.23)$ & $49.51[35.85,70.05]$ & 0.127 \\
\hline
\end{tabular}

Data are means $\pm S D$ or medians (interquartile range) or $\mathrm{n}(\%)$

$A E C I / A R B$ Angiotensin Converting Enzyme Inhibitors/Angiotensin receptor antagonist, CCB Ca-Antagonists, SBP systolic blood pressure, DBP diastolic blood pressure, $B M I$ body mass index, $F B G$ fasting blood glucose, $T G$ triglycerides, $T C$ total cholesterol, $L D L-C$ low-density lipoprotein cholesterol, $H D L-C$ high-density lipoprotein cholesterol, SCr serum creatinine, UA uric acid, UACR urinary albumin creatinine ratio, eGFR estimated glomerular filtration rate, FINS fasting serum insulin, HOMA-IR homeostasis model assessment for insulin resistance, HOMA- $\beta$ homeostasis model assessment for $\beta$-cell function

triphosphate cyclohydrolase-I expression and protect endothelial function $[3,4]$. Several studies have shown that $\mathrm{BH} 4$ can improve endothelial function in patients with diabetes and hypercholesterolemia [12-14]. A study by $\mathrm{Xu}$ et al. [15] showed that PPAR $\alpha$ or AMP-activated protein kinase $\alpha(\mathrm{AMPK} \alpha)$ inhibitors can reverse vasodilation of the aorta. Treatment of fenofibrate can increase the expression of PPAR and induce liver kinase B1 (LKB1) translocation and activation of AMPK, thus activating nitric oxide synthase 3 (eNOS), improving endothelium-dependent dilation of vessels, increasing nitric oxide (NO) levels, and decreasing the role of renal injury markers and the vasoconstrictor prostaglandin. Several animal studies have shown $[16,17]$ that fenofibrate treatment of $\mathrm{db} / \mathrm{db}$ mice can not only reduce the expansion of mesangial matrix and glomerular hypertrophy, but also reduce collagen deposition and the expression of transforming growth factor-1 in renal tissue, 
Table 2 The changes of Clinical characteristics after 90 and 180 days follow up

\begin{tabular}{|c|c|c|}
\hline Group & $\begin{array}{l}\text { Control } \\
(n=28)\end{array}$ & $\begin{array}{l}\text { Fenofibrate treatment } \\
(n=28)\end{array}$ \\
\hline \multicolumn{3}{|l|}{$\mathrm{SBP}(\mathrm{mmHg})$} \\
\hline 90 days & $-2.00(-7.00,3.00)$ & $-1.00(-3.00,-1.00)$ \\
\hline 180 days & $-2.50(-8.00,5.00)$ & $-1.00(-7.00,4.00)$ \\
\hline \multicolumn{3}{|c|}{ DBP ( mmHg) } \\
\hline 90 days & $-0.80(-3.00,4.00)$ & $-1.00(-3.00,-1.00)$ \\
\hline 180 days & $-1.00(-2.00,5.00)$ & $-1.20(-2.00,0.25)$ \\
\hline \multicolumn{3}{|l|}{$\mathrm{BMl}, \mathrm{kg} / \mathrm{m}^{2}$} \\
\hline 90 days & $-0.26(-1.56,0.12)$ & $-0.20(-1.16,0.15)$ \\
\hline 180 days & $-0.22(-1.32,0.17)$ & $-0.21(-1.01,0.22)$ \\
\hline \multicolumn{3}{|c|}{$\mathrm{FPG}, \mathrm{mmol} / \mathrm{L}$} \\
\hline 90 days & $-0.43(-1.70,0.50)$ & $-0.37(-1.77,0.32)$ \\
\hline 180 days & $-0.24(-2.44,0.39)$ & $-0.68(-2.81,0.19)$ \\
\hline \multicolumn{3}{|l|}{$\mathrm{HbA} 1 \mathrm{c}, \%$} \\
\hline 90 days & $-0.60(-1.30,0.10)$ & $-0.40(-1.35,-0.10)$ \\
\hline 180 days & $-0.90(-1.40,-0.25)$ & $-0.70(-1.38,-0.10)$ \\
\hline \multicolumn{3}{|l|}{$\mathrm{TG}, \mathrm{mmol} / \mathrm{L}$} \\
\hline 90 days & $-0.64(-0.96,0.42)$ & $-1.27(-1.77,-0.24) *$ \\
\hline 180 days & $-0.22(-1.21,0.19)$ & $-1.91(-1.12,-0.53)$ \# \\
\hline \multicolumn{3}{|l|}{$\mathrm{TC}, \mathrm{mmol} / \mathrm{L}$} \\
\hline 90 days & $-0.19(-1.26,0.11)$ & $-0.19(-0.77,-0.19)$ \\
\hline 180 days & $0.22(-0.29,0.53)$ & $-0.21(-0.87,0.31)$ \\
\hline \multicolumn{3}{|c|}{ LDL-C, mmol/L } \\
\hline 90 days & $-0.10(-0.80,0.10)$ & $-0.15(-0.50,0.72)$ \\
\hline 180 days & $0.25(-0.18,0.40)$ & $-0.20(-0.40,0.40)$ \\
\hline \multicolumn{3}{|c|}{$\mathrm{HDL}-\mathrm{C}, \mathrm{mmol} / \mathrm{L}$} \\
\hline 90 days & $0.00(0.00,0.01)$ & $0.20(0.10,0.20) *$ \\
\hline 180 days & $0.00(0.00,0.01)$ & $0.16(0.00,0.22){ }^{\#}$ \\
\hline \multicolumn{3}{|l|}{$\mathrm{Scr}, \mu \mathrm{mol} / \mathrm{L}$} \\
\hline 90 days & $1.70(-2.40,5.20)$ & $7.60(3.80,12.40) *$ \\
\hline 180 days & $4.35(-0.95,9.80)$ & $4.25(-1.75,15.60)$ \\
\hline \multicolumn{3}{|l|}{ UA, $\mu \mathrm{mol} / \mathrm{L}$} \\
\hline 90 days & $0.00(-60.00,45.00)$ & $-92.5(-145,-21) *$ \\
\hline 180 days & $-16.00(-43.75,-16.00)$ & $-66(-111.00,-34.00) \#$ \\
\hline \multicolumn{3}{|l|}{ UACR, mg/g } \\
\hline 90 days & $-20.87(-61.16,15.72)$ & $-41.39(-103.81,-1.44)$ \\
\hline 180 days & $-8.15(-59.69,41.94)$ & $-44.05(-179.47,-12.16)$ \\
\hline \multicolumn{3}{|c|}{ eGFR $\mathrm{ml} / \mathrm{min} / 1.73 \mathrm{~m}^{2}$} \\
\hline 90 days & $-2.27(-7.33,4.63)$ & $-9.25(-22.10,-8.28) *$ \\
\hline 180 days & $-5.63(-12 \cdot 10,1 \cdot 12)$ & $-7.26(-21.34,-1.37)$ \\
\hline \multicolumn{3}{|l|}{$\mathrm{FINS}, \mu \mathrm{IU} / \mathrm{mL}$} \\
\hline 90 days & $-0.60(-3.45,2.12)$ & $-0.90(-4.50,2.10)$ \\
\hline 180 days & $-0.25(-5.15,2.35)$ & $-1.40(-6.90,1.81)$ \\
\hline
\end{tabular}

Table 2 The changes of Clinical characteristics after 90 and 180 days follow up (Continued)

\begin{tabular}{|c|c|c|}
\hline Group & $\begin{array}{l}\text { Control } \\
(n=28)\end{array}$ & $\begin{array}{l}\text { Fenofibrate treatment } \\
(n=28)\end{array}$ \\
\hline \multicolumn{3}{|l|}{ HOMA-IR } \\
\hline 90 days & $-0.35(-1.98,0.64)$ & $-0.25(-2.77,0.45)$ \\
\hline 180 days & $-1.09(-2.68,-1.09)$ & $-0.94(-3.15,0.58)$ \\
\hline \multicolumn{3}{|l|}{ HOMA- $\beta$} \\
\hline 90 days & $6.19(-38.88,20.64)$ & $3.62(-6.21,25.04)$ \\
\hline 180 days & $6.98(-39.58,34.25)$ & $4.75(-21.91,30.38)$ \\
\hline \multicolumn{3}{|c|}{$\begin{array}{l}\text { Data are means } \pm S D \text { or medians (interquartile range) or } n(\%) \\
A E C I / A R B \text { Angiotensin Converting Enzyme Inhibitors/Angiotensin receptor } \\
\text { antagonist, SBP systolic blood pressure, DBP diastolic blood pressure, BMI body } \\
\text { mass index, } B B G \text { fasting blood glucose, TG triglycerides, TC total cholesterol, } \\
\text { LDL-C low-density lipoprotein cholesterol, HDL-C high-density lipoprotein } \\
\text { cholesterol, } S C r \text { serum creatinine, UA uric acid, UACR urinary albumin to } \\
\text { creatinine ratio, eGFR estimated glomerular filtration rate, FINS fasting serum } \\
\text { insulin, HOMA-IR homeostasis model assessment for insulin resistance, HOMA- } \beta \\
\text { homeostasis model assessment for } \beta \text {-cell function }\end{array}$} \\
\hline
\end{tabular}

thus significantly reducing proteinuria and glomerular fibrosis. The Diabetes Atherosclerosis Intervention Study (DAIS) showed that worsening of albumin excretion was reduced after the fenofibrate treatment [18]. The FIELD study suggested that treatment of fenofibrate can reduce albuminuria and prevent the progression of DN $[5,6]$. The ACCORD study suggested that [7] a lower incidence of both micro-albuminuria and macroalbuminuria was noted in the fenofibrate group. A small sample size study showed that gemfibrozil might mitigate the progression of microalbuminuria in noninsulin-dependent diabetic patients [19]. A study by Frazier et al. [20] showed that there is lower incidence of microalbuminuria after treatment with fenofibrate for 4 years. These results suggest that the use of fenofibrate may improve lipid toxicity induced by renal lipid accumulation, resulting in decreased urinary microalbumin. We noticed that the increase in Scr and the decrease in eGFR in the treatment group was greater than that in the control group at the 90 days. There was no difference between the two groups in increase in Scr and decrease in eGFR at 180 days. This result was similar to the previous experiment [21-23]. Although there was no good explanation for this phenomenon, we thought the GFR was higher in the early stages of diabetic nephropathy, as the blood sugar and blood lipid decreased, the high filtration state was improved in the short term, so in the treatment group, the rise of creatinine and the decline of GFR were significantly more obvious.

Our study showed that UA levels were significantly lower after fenofibrate treatment. Correlation analysis showed that the decrease in UACR was positively associated with the decrease in UA after fenofibrate treatment. Jung [24] et al. study show that fenofibrate have an additionally role of reducing UA levels in patients having 


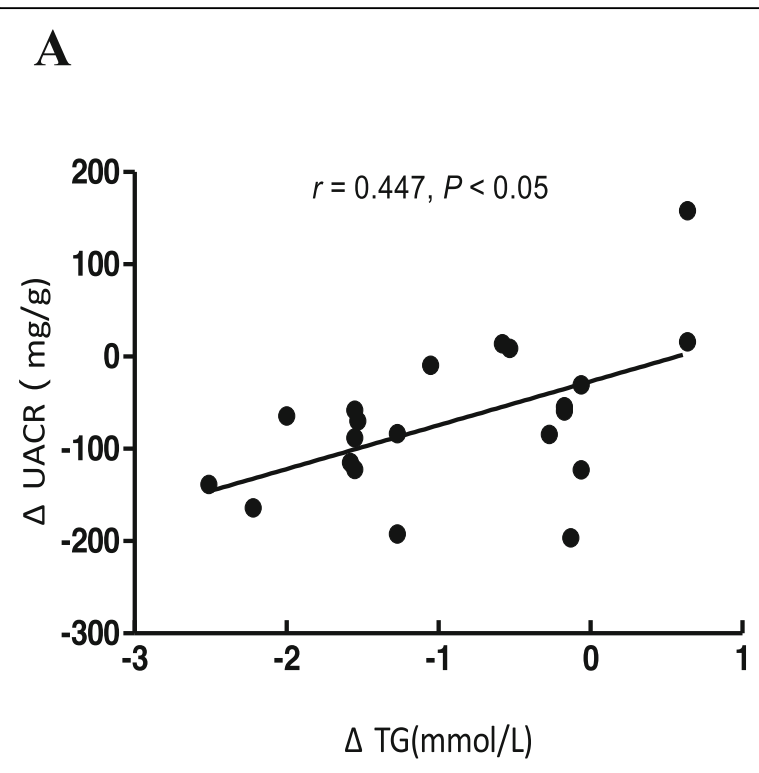

B

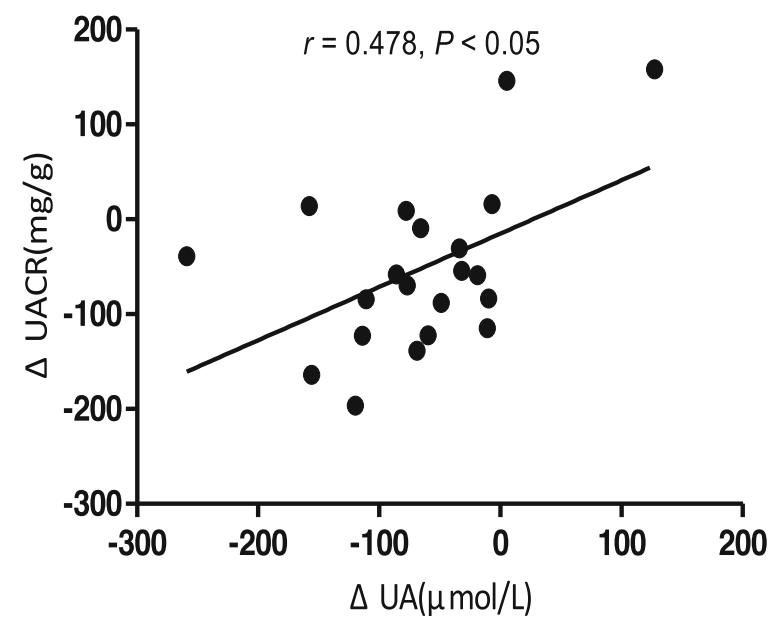

Fig. 1 Correlations between the decrease in UACR and changes of TG and UA after fenofibrate treatment

high TG levels. Several [25-28] studies have shown that fenofibrate can reduce UA levels in patients, especially in those patients with coexisting hyperlipidemia. It is believed that fenofibrate can reduce serum UA levels by increasing UA excretion. Several studies have reported [29] that fenofibrate could inhibit the renal organic anion transporter urate transporter 1 and increase urinary excretion of UA to decrease serum UA levels. Several studies [30-32] have shown that serum UA and microalbuminuria are significantly positively associated in T2DM patients.

\section{Limitations}

Our study had several limitations. The present study is small and single-center, and the results may be biased; thus, it requires further confirmation by large-scale, multi-center clinical studies. Moreover, it would be better if there were cell-based and animal studies to demonstrate our result.

\section{Conclusions}

Fenofibrate could reduce progression to microalbuminuria and does not increase eGFR impairment in T2DM patients with hypertriglyceridemia.

\section{Abbreviations}

T2DM: Type 2 diabetes mellitus; UACR: Urinary microalbumin /creatinine ratio; FBG: Fasting blood glucose; HbA1c: Glycosylated hemoglobin; UA: Uric acid; TG: Triglyceride; HDL-C: High-density lipoprotein cholesterol;

DN: Diabetic nephropathy; FIELD: The fenofibrate intervention and event lowering in diabetes; ACCORD: The action to control cardiovascular risk in diabetes; eGFR: estimated glomerular filtration rate; WHO: World Health Organization; CVD: Cardiovascular disease; MDRD: Modification of diet in renal disease; TC: Total cholesterol; LDL-C: Low-density lipoprotein cholesterol; Scr: Serum creatinine; UA: Uric acid; BMI: Body mass index; HOMA-IR: Homeostasis model assessment index of insulin resistance; HOMA$\beta$ : Homeostasis model assessment for $\beta$-cell function; SBP: Systolic blood pressure; DBP: Diastolic blood pressure; PPARa: Peroxisome proliferatoractivated receptor a; BH4: Tetrahydrobiopterin; AMPKa: AMP-activated protein kinase $\alpha_{;}$LKB1: Liver kinase B1; eNOS: Activating nitric oxide synthase 3; NO: Nitric oxide; DAIS: The diabetes atherosclerosis intervention study

\section{Acknowledgments}

We would like to thank the participants for participating in this study.

\section{Authors' contributions}

XM Sun contributed to acquisition of data, analyzed the data and was a major contributor in writing the manuscript. J Liu performed statistical analysis. G Wang reviewed the manuscript. All authors read and approved the final manuscript.

\section{Funding}

This work was supported by grants from the Chinese National Natural Science Foundation (No. 81600657) and Capital Funds for Health Improvement and Research (No. 2018-4-2034) to J.L.; and the Chinese National Natural Science Foundation (No. 81770792) and Capital Clinical Research Foundation of Beijing Municipal Commission of Science and Technology (No. Z161100000516069) to G.W.

\section{Availability of data and materials}

The datasets generated and/or analysed during the current study are not publicly available due individual privacy but are available from the corresponding author on reasonable request.

\section{Ethics approval and consent to participate}

The study received approval from the Ethics Committee of Beijing Chaoyang Hospital. All participants gave their written, informed consent to participate.

Consent for publication

Not applicable.

Competing interests

The authors declare that they have no competing interests. 
Received: 28 December 2019 Accepted: 31 March 2020

Published online: 23 May 2020

\section{References}

1. Locatelli F, Pozzoni P, Del VL. Renal replacement therapy in patients with diabetes and end-stage renal disease. J Am Soc Nephrol. 2004;15(Suppl 1): 25-9.

2. Liu J, Lu R, Wang Y, Hu Y, Jia Y, Yang N, et al. PPARa Agonist Fenofibrate Reduced the Secreting Load of $\beta$-Cells in Hypertriglyceridemia Patients with Normal Glucose Tolerance. PPAR Res. 2016;2016:6232036.

3. Liu J, Lu C, Li F, He W, He L, Hao Y, et al. PPAR a Agonist Fenofibrate Upregulates Tetrahydrobiopterin Level through Increasing the Expression of Guanosine Triphosphate Cyclohydrolase-I in Human Umbilical Vein Endothelial Cells. PPAR Res. 2011;2011:523520.

4. Wang G, He L, Liu J, Yu J, Feng X, Li F, et al. Coronary flow velocity reserve is improved by PPAR-a agonist fenofibrate in patients with hypertriglyceridemia. Cardiovasc Ther. 2013;31:161-7.

5. Keech A, Drury P, Davis TM, Davis TM, Donoghoe M, Whiting M, et al. Protection against nephropathy with fenofibrate in type 2 diabetes mellitus: the FIELD study. Circulation. 2009;120:419-20.

6. Zambon A, Cusi K. The role of fenofibrate in clinical practice. Diab Vasc Dis Re. 2007:4:15-20.

7. Ginsberg HN, Elam MB, Lovato LC, Crouse JR, Lawrence AL, Endou H, et al. Effects of combination lipid therapy in type 2 diabetes mellitus. N Engl J Med. 2010;362:1563-74.

8. American Diabetes Association. Diagnosis and classification of diabetes mellitus. Diabetes Care. 2013;36(Suppl 1):67-74.

9. Fioretto $\mathrm{P}$, Mauer M. Histopathology of diabetic nephropathy. Semin Nephrol. 2007;27:195-207.

10. Thompson J, Wilson P, Brandewie K, Taneja D, Schaefer L, Mitchell B, et al. Renal accumulation of biglycan and lipid retention accelerates diabetic nephropathy. Am J Pathol. 2011;179:1179-87.

11. Chung S, Park CW. Role of peroxisome proliferator-activated receptor a in diabetic nephropathy. Diabetes Metab J. 2011;5:327-36.

12. Kintscher U, Lyon C, Wakino S, Bruemmer D, Feng X, Goetze S, et al PPARalpha inhibits TGF-beta-induced beta5 integrin transcription in vascular smooth musclecells by interacting with Smad4. Circ Res. 2002;91:35-44.

13. Heitzer T, Krohn K, Albers S, Meinertz T. Tetrahydrobiopterin improves endothelium-dependent vasodilation by increasing nitric oxide activity in patients with type II diabetes mellitus. Diabetologia. 2000;43:1435-8.

14. Cosentino F, Hurlimann D, Delli Gatti C, Chenevard R, Blau N, Channon KM, et al. Chronic treatment with tetrahydrobiopterin reverses endothelial dysfunction and oxidative stress in hypercholesterolaemia. Heart. 2007;94: 487-92.

15. Xu N, Wang Q, Jiang S, Xie L, Chen J, Zhou S, et al. Fenofibrate improves vascular endothelial function and contractility in diabetic mice. Redox Biol. 2019;20:87-97.

16. Park CW, Zhang Y, Zhang X, Wu J, Chen L, Cha DR, et al. PPAR alpha agonist fenofibrate improves diabetic nephropathy in $\mathrm{db} / \mathrm{db}$ mice. Kidney Int. 2006:69:1511-7.

17. Cha DR, Zhang X, Zhang Y, Wu J, Su D, Han JY, et al. Peroxisome proliferator activated receptor alpha/gamma dual agonist tesaglitazar attenuatesdiabetic nephropathy in db/db mice. Diabetes. 2007;56:2036-45.

18. Ansquer JC, Foucher C, Rattier S, Taskinen MR, Steiner G. Fenofibrate reduces progression to microalbuminuria over 3 years in the placebo controlled study in type 2 diabetes: results from the diabetes atherosclerosis intervention study (DAIS). Am J Kidney Dis. 2005;45:485-93.

19. Smulders YM, Van Eeden AE, Stehouwer CDA, Weijers RN, Slaats EH, Silberbusch J. Can reduction of hypertriglyceridaemia slow progression of microalbuminuria in patients with non-insulin-dependent diabetes mellitus? Eur J Clin Investig. 1997;27:997-1002.

20. Frazier R, Mehta R, Cai X, Lee JW, Napoli S, et al. Associations of Fenofibrate therapy with incidence and progression of CKD in patients with type 2 diabetes. Kidney Int Rep. 2018;4:94-102.

21. Hottelart C, el Esper N, Achard JM, Pruna A, Fournier A. Fenofibrate increases blood creatinine, but does not change the glomerular filtration rate in patients with mild renal insufficiency. Nephrologie. 1999;20:41-4.

22. Ansquer JC, Dalton RN, Caussé E, Crimet D, Le Malicot K, Foucher C. Effect of Fenofibrate on Kidney Function: A 6-Week Randomized. Am J Kidney Dis. 2008;51:904-13.
23. Bonds DE, Craven TE, Buse J, Crouse JR, Cuddihy R, Elam M, et al. Fenofibrate-associated changes in renal function and relationship to clinical outcomes among individuals with type 2 diabetes: the action to control cardiovascular risk in diabetes (ACCORD) experience. Diabetologia. 2012;55: $1641-50$.

24. Jung JY, Choi Y, Suh $\mathrm{CH}$, Yoon D, Kim HA. Effect of fenofibrate on uric acid level in patients with gout. Sci Rep. 2018;8:16767.

25. Derosa G, Maffioli P, Sahebkar A. Plasma uric acid concentrations are reduced by fenofibrate: a systematic review and meta-analysis of randomized placebo-controlled trials. Pharmacol Res. 2015;102:63-70.

26. Feher MD, Hepburn AL, Hogarth MB. Fenofibrate enhances urate reduction in men treated with allopurinol for hyperuricaemia and gout. Rheumatology. 2003;42:321-5.

27. Lee $\mathrm{YH}$, Lee $\mathrm{CH}$, Lee J. Effect of fenofibrate in combination with urate lowering agents in patients with gout. Korean J Intern Med. 2006:21:89-93.

28. Noguchi Y, Tatsuno I, Suyama K, Shibata T, Yoshida T, Otsuka Y, et al. Effect of fenofibrate on uric acid metabolism in Japanese hyperlipidemic patients. Atheroscler Thromb. 2004;11:335-40.

29. Uetake D, Ohno I, Ichida K, Yamaguchi Y, Saikawa H, Endou H, et al. Effect of fenofibrate on uric acid metabolism and urate transporter 1. Intern Med. 2010;49:89-94.

30. Latif H, lqbal A, Rathore R, Butt NF. Correlation between serum uric acid level and microalbuminuria in Type-2 diabetic nephropathy. Pak J Med Sci. 2017:33:1371-5.

31. Neupane S, Dubey RK, Gautam N, Agrawal KK, Jayan A, Shrestha S, et al. Association between serum uric acid, urinary albumin excretion, and glycated hemoglobin in type 2 diabetic patient. Niger Med J. 2016;57:11923.

32. Behradmanesh S, Horestani MK, Baradaran A, Nasri H. Association of serum uric acid with proteinuria in type 2 diabetic patients. J Res Med Sci. 2013;18: 44-6.

\section{Publisher's Note}

Springer Nature remains neutral with regard to jurisdictional claims in published maps and institutional affiliations.

Ready to submit your research? Choose BMC and benefit from:

- fast, convenient online submission

- thorough peer review by experienced researchers in your field

- rapid publication on acceptance

- support for research data, including large and complex data types

- gold Open Access which fosters wider collaboration and increased citations

- maximum visibility for your research: over $100 \mathrm{M}$ website views per year

At $\mathrm{BMC}$, research is always in progress.

Learn more biomedcentral.com/submissions 